\title{
Experiences with Surgical treatment of chronic lower limb ulcers at a Tertiary hospital in northwestern Tanzania: A prospective review of 300 cases
}

Fidelis Mbunda ${ }^{1 \dagger}$, Mabula D Mchembe ${ }^{2}$, Phillipo L Chalya ${ }^{1 *}$, Peter Rambau ${ }^{3 \dagger}$, Stephen E Mshana ${ }^{4 \dagger}$, Benson R Kidenya ${ }^{5}$ and Japhet M Gilyoma ${ }^{1}$

\begin{abstract}
Background: Chronic lower limb ulcers constitute a major public health problem of great important all over the world and contribute significantly to high morbidity and long-term disabilities. There is paucity of information regarding chronic lower limb ulcers in our setting; therefore it was necessary to conduct this study to establish the patterns and outcome of chronic lower limb ulcers and to identify predictors of outcome in our local setting.

Methods: This was a descriptive prospective study of patients with chronic lower limb ulcers conducted at Bugando Medical Centre between November 2010 and April 2012. Ethical approval to conduct the study was sought from relevant authorities. Statistical data analysis was done using SPSS version 17.0 and STATA version 11.0.

Results: A total of 300 patients were studied. Their ages ranged from 3 months to 85 years (median 32 years). The male to female ratio was 2:1. The median duration of illness was 44 days. Traumatic ulcer was the most frequent type of ulcer accounting for $60.3 \%$ of patients. The median duration of illness was 44 days. The leg was commonly affected in 33.7\% of cases and the right side (48.7\%) was frequently involved. Out of 300 patients, 212 (70.7\%) had positive aerobic bacterial growth within 48 hours of incubation. Pseudomonas aeruginosa (25.5\%) was the most frequent gram negative bacteria isolated, whereas gram positive bacteria commonly isolated was Staphylococcus aureus (13.7\%). Twenty (6.7\%) patients were HIV positive with a median CD4+ count of 350 cells/ $\mu$ l. Mycological investigation was not performed. Bony involvement was radiologically reported in $83.0 \%$ of cases. Histopathological examination performed in 56 patients revealed malignancy in 20 (35.7\%) patients, of which malignant melanoma (45.0\%) was the most common histopathological type. The vast majority of patients, 270 (90.0\%) were treated surgically, and surgical debridement was the most common surgical procedure performed in $24.1 \%$ of cases. Limb amputation rate was $8.7 \%$. Postoperative complication rate was $58.3 \%$ of which surgical site infection (77.5\%) was the most common post-operative complications. The median length of hospital stay was 23 days. Mortality rate was 4.3\%. Out of the two hundred and eighty-seven (95.7\%) survivors, 253 (91.6\%) were treated successfully and discharged well (healed). After discharge, only $35.5 \%$ of cases were available for follow up at the end of study period.

(Continued on next page)
\end{abstract}

\footnotetext{
* Correspondence: drphillipoleo@yahoo.com

${ }^{\dagger}$ Equal contributors

${ }^{1}$ Department of Surgery, Catholic University of Health and Allied Sciences-

Bugando, Mwanza, Tanzania

Full list of author information is available at the end of the article
} 
(Continued from previous page)

Conclusion: Chronic lower limb ulcers remain a major public health problem in this part of Tanzania. The majority of patients in our environment present late when the disease is already in advanced stages. Early recognition and aggressive treatment of the acute phase of chronic lower limb ulcers at the peripheral hospitals and close follow-up are urgently needed to improve outcomes of these patients in our environment.

Keywords: Chronic lower limb ulcers, Patterns, Treatment outcome, Predictors of outcome, Tanzania

\section{Background}

Chronic ulceration of the lower limb constitutes a major public health problem of great important all over the world and contributes significantly to high morbidity and long-term disabilities [1]. It is a stressful disease to those affected as well as their family and the community in general, and its impact on hospital resources is great due to prolonged hospitalization, high cost of health care, loss of productivity and reduced quality of life [1-3]. Lower limb ulceration presenting late may end up being treated by limb amputation and is associated with increased risk of recurrence and malignant change [3].

Globally, the prevalence of chronic lower limb ulcers in the community has been reported in literature to range from 1.9 to $13.1 \%$ [1-3]. In developed countries, chronic ulceration of the lower limb affects approximately $2 \%$ of the population [4]. In the United Kingdom, the prevalence of chronic lower limb ulcers in the adult population is $1 \%$ and the prevalence in the more than 65 years age group is $3-5 \%[4,5]$. In the United States of America, approximately 6,000,000 new lower limb ulcer cases are reported each year and in Sweden, 4-5\% of the population over the age of 80 years presents with this pathology. The annual cost for treating chronic lower limb ulceration patients globally is estimated at some $\$ 25$ million $[6,7]$.

In Tanzania, chronic lower limb ulceration continues to be one of the leading causes of morbidity and long term disabilities. The disease tends to affect the young, reproductive age group. Observation at Bugando Medical Centre shows; chronic lower extremity ulceration is the single commonest indication for admission reported in the surgical wards and the majority of patients present late with advanced disease [8]. The etiological patterns of lower extremity ulceration in most developing countries have been reported to differ from that in developed countries. While, most of lower limb ulceration in the Western population is related to vascular diseases such as venous and arterial disease; trauma, malignancies, diabetes mellitus and infections are the most common causes in developing countries $[2,9,10]$.

The effective treatment and outcome of lower limb ulceration is highly dependent upon establishing the etiology of the ulceration and the identification of other associated conditions that may have an adverse effect on healing [11].
The majority of chronic lower limb ulcers are preventable and have a multifactorial etiology, therefore understanding the etiological pattern of this condition in our local setting will provides information that is important for accurate diagnosis, prediction of outcome and may help in hospital resource allocations and establishment of prevention strategies as well as treatment protocols [12].

The aim of this study was to describe the patterns and treatment outcome of chronic lower limb ulcers in our local setting and to identify factors predicting the outcome. The study provides basis for establishment of treatment guidelines as well as prevention strategies.

\section{Methods}

\section{Study design and setting}

This was a descriptive prospective hospital-based study of patients with chronic lower limb ulcers carried out at Bugando Medical Centre (BMC) in Northwestern Tanzania between November 2010 and February 2012. BMC is located in Mwanza city along the shore of Lake Victoria in the northwestern part of Tanzania. It is a tertiary care and teaching hospital for the Catholic University of Health and Allied Sciences- Bugando (CUHAS-Bugando) and other paramedics and has a bed capacity of 1000 . BMC is one of the four largest referral hospitals in the country and serves as a referral centre for tertiary specialist care for a catchment population of approximately 13 million people from Mwanza, Mara, Kagera, Shinyanga, Tabora and Kigoma regions.

\section{Study subjects and procedures}

The study included all patients with chronic lower limb ulcers of all age groups and both genders seen in the surgical wards and surgical outpatient clinics of BMC during the study period. Patients who failed to consent for the study, treatment (e.g. limb amputation) and HIV testing were excluded from the study.

Recruitment of patients to participate in the study was done at the Accident and Emergency department, surgical outpatient clinic and in the surgical wards. Patients were screened for inclusion criteria and those who met the inclusion criteria were offered explanations about the study and requested to consent before being enrolled into the study. Convenience sampling of patients who 
met the inclusion criteria was performed until the sample size was reached. The diagnosis of chronic lower limb ulcers was made by clinical history and physical examination and chronic lower limb ulcers was defined as defect in the skin on the lower extremities that remains unhealed for at least four or more weeks. Pus or pus swabs were obtained from the ulcer and transported to the laboratory within an hour of collection. In the laboratory, the specimens were registered in the log books and processed as per standard operative procedures. Bacterial identification was done using an in house biochemical panel [13]. Antibacterial susceptibility testing to various antibiotics was performed using disc diffusion methods as previously described $[14,15]$. In addition, blood was taken from all patients for random blood sugar testing and CD4 enumeration in HIV positive patients. HIV test was done using national algorithm of rapid test. Mycological investigation was not performed due to logistic problems. Biopsies from chronic lower limb ulcers were taken under sterile technique and specimens were transported in a formalin solution to the histopathology laboratory for processing.

All recruited patients were managed accordingly. The authors ensured that the study patients were receiving the appropriate treatment and supportive care as prescribed by the surgeon. Patients were followed up until discharge or death. After discharge patients were followed up at our surgical outpatient clinic for up to six months.

Data were collected using a pre-tested coded questionnaire. Data administered in the questionnaire included; patients characteristics (e.g. age, sex, premorbid illness, history of smoking and use of immunosuppressive drugs), causes of chronic lower limb ulcers, clinical pattern, investigations, treatment modalities and postoperative complications. Length of hospital stay (LOS) and mortality were recorded at the end of study period.

\section{Statistical data analysis}

Statistical data analysis was done using SPSS software version 17.0 (SPSS, Inc, Chicago, IL) and STATA version 11.0. Data was summarized in form of proportions and frequent tables for categorical variables. Continuous variables were summarized using means, median, mode and standard deviation. P-values were computed for categorical variables using Chi - square $\left(x^{2}\right)$ test and Fisher's exact test depending on the size of the data set. Independent student $t$-test was used for continuous variables. Multivariate logistic regression analysis was used to determine predictor variables that are associated with outcome. Post-operative complications were entered into univariate and multivariate analysis after been categorized into presence or absence of post-operative complications. LOS was arbitrarily categorized as $\leq 14$ and $>14$ days. A p-value of less than 0.05 was considered to constitute a statistically significant difference.

\section{Ethical consideration}

Ethical approval to conduct the study was obtained from the CUHAS-Bugando/BMC joint institutional ethic review committee before the commencement of the study. Informed consent was sought from each patient before being enrolled into the study.

\section{Results}

During the period under study, a total of 312 patients with chronic lower limb ulcers were managed at Bugando Medical Centre. Of these, 12 patients were excluded from the study due failure to meet the inclusion criteria. Thus, 300 patients were studied. The ages of the study population ranged from 3 months to 85 years with a median of 32 years. The modal age group was 21-30 years. Out of 300 patients recruited into the study, two hundred (66.7\%) were males and 100 (33.3\%) were females. The male to female ratio was 2:1 with a male predominance in each age group (Figure 1).

Fifty-four (18.0\%) patients presented with history of premorbid illness such as diabetes mellitus in 32 (59.3\%), chronic pulmonary diseases in 8 (14.8\%), hypertension in $6(11.1 \%)$, peripheral vascular diseases in 4 (7.4\%) and congenital cardiac diseases and obstructive jaundice in $2(3.7 \%)$ patients each respectively. In this study, sixty-eight (22.7\%) patients had history of cigarette smoking. There was no history of immunosuppressive drugs use or radiotherapy.

The median duration of illness was 44 days (range 31 to 3218 days). Traumatic ulcers were the most frequent type of ulcer accounting for $60.3 \%$ of patients. Road traffic accidents (RTAs) were the most common cause of traumatic ulcers accounting for 122 (67.4\%) patients (Table 1). Seventy-three (59.8\%) of RTAs were related to motorcycle injuries. Other causes of traumatic ulcers included burn in 45 (24.9\%), falls in 8 (4.4\%), gunshot injuries in $3(1.7 \% 0$, hit by falling object and sport injuries

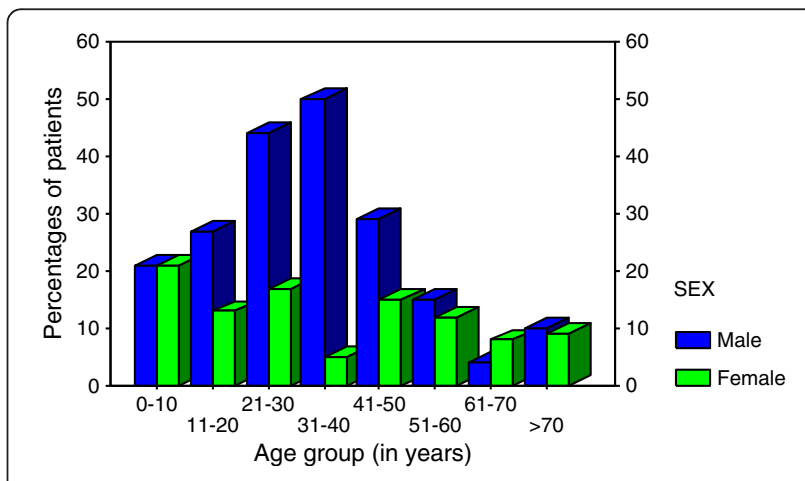

Figure 1 Sex distribution according to age group (In years). 
Table 1 Distribution of study population according to the type of ulcers

\begin{tabular}{|c|c|c|}
\hline Type of ulcers & Frequency & Percentage \\
\hline Traumatic ulcers & 181 & 60.3 \\
\hline - Mechanical trauma & 131 & 72.4 \\
\hline - Burns & 50 & 27.6 \\
\hline Infective ulcers & 43 & 14.3 \\
\hline - Osteomyelitis & 30 & 69.8 \\
\hline - Tropical ulcer & 6 & 13.9 \\
\hline - Cellulitis & 5 & 11.6 \\
\hline . Others & 2 & 4.7 \\
\hline Metabolic ulcers & 35 & 11.7 \\
\hline - Diabetic ulcer & 32 & 91.4 \\
\hline - Pellagra & 3 & 8.6 \\
\hline Neoplastic/malignant ulcers & 20 & 6.7 \\
\hline - Malignant melanoma & 9 & 45.0 \\
\hline - Kaposi's sarcoma & 5 & 25.0 \\
\hline - Squamous cell carcinoma & 4 & 20.0 \\
\hline . Others & 2 & 10.0 \\
\hline Vascular ulcers & 11 & 3.7 \\
\hline - Arterial ulcers & 5 & 45.5 \\
\hline - Venous ulcers & 4 & 36.4 \\
\hline - Mixed ulcers & 2 & 18.2 \\
\hline Neuropathic ulcers & 8 & 2.7 \\
\hline - Pressure sores & 6 & 75.0 \\
\hline - Others & 2 & 25.0 \\
\hline $\begin{array}{l}\text { Ulcerating skin lesions e.g. } \\
\text { Pyogenic Granulomatous }\end{array}$ & 2 & 0.7 \\
\hline
\end{tabular}

in $2(1.1 \%)$ and $1(0.6 \%)$ respectively. Table 1 shows distribution of study population according to the type of ulcers.

The leg was commonly affected in $33.7 \%$ of cases (Figure 2) and the right, left and both limbs were involved in 146 (48.7\%), $126(42.0 \%)$ and 28 (9.3\%) patients respectively. The size ulcers ranged from 2 to $30 \mathrm{~cm}$ with a median of $5 \mathrm{~cm}$.

Out of 300 patients with CLLUs, 212 (70.7\%) had positive aerobic bacterial growth within 48 hours of incubation. Of these, 10 (4.7\%) patents had polymicrobial growth. Pseudomonas spp. (25.5\%) and Proteus spp. (21.2\%) were the most common bacteria isolated, while the least isolated bacteria were Enterobacter spp (2.8\%) and Enterococcus spp (1.4\%). Forty-one (19.3\%) bacterial isolates were found to be Extended Spectrum BetaLactamases (ESBL) producers (i.e. resistant to first, second, third and fourth generation cephalosporins). Methicilin Resistant Staphylococcus aureus (MRSA) was detected in 23 out of 29 (79.3\%) Staphylococcus aureus isolates.

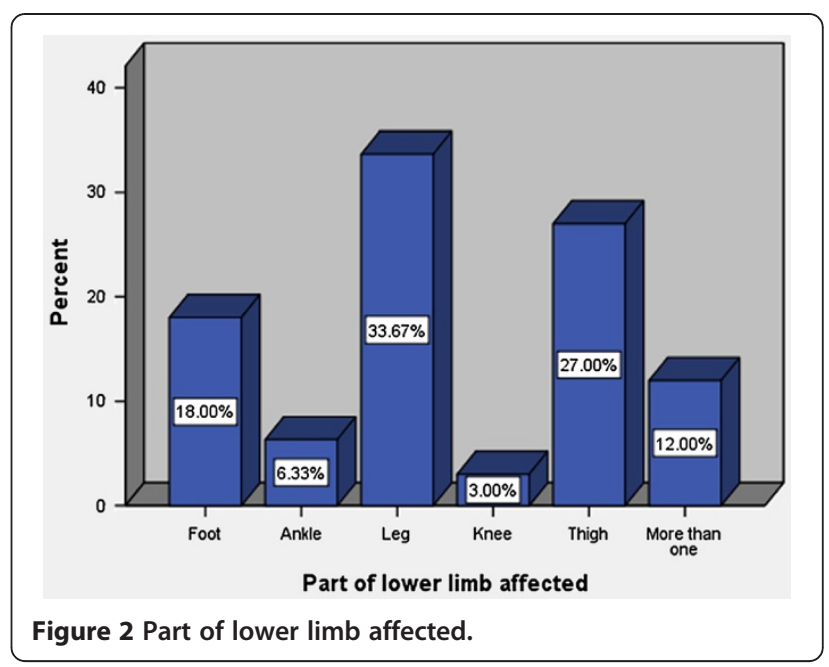

In this study, twenty (6.7\%) patients were HIV positive. Of these, 6 (30.0\%) patients were known cases on antretroviral therapy (ARV) and the remaining 14 (70.0\%) patients were newly diagnosed patients. Their CD 4+ count, available in 15 patients, ranged from 180 to 480 cells $/ \mu \mathrm{l} \quad($ median $=350$ cells $/ \mu \mathrm{l})$. A total of two HIV patients (13.3\%) had CD4+ count below 200 cells/ $\mu$ l and the remaining 13 patients $(86.7 \%)$ had CD4+ count of $\geq 200$ cells $/ \mu$.

Plain $\mathrm{x}$-rays of the affected limbs were performed in 235 (78.3\%) patients. Of these, 195 (83.0\%) patients had abnormal x-ray findings including associated fractures, chronic osteomyelitis, bone tumors and others in 144 (73.9\%), 47 (24.1\%), 3 (1.5\%) and $1(0.5 \%)$ patients respectively.

Doppler ultrasound of the affected limbs was done in $203(67.7 \%)$ patients. Of these, only seventeen (8.4\%) patients had abnormal Doppler ultrasound findings.

A total of 56 histopathological examinations were performed. Of these, 20 (35.7\%) had a histopathologically proven malignancy, of which malignant melanoma was the most common histopathological type in 9 (45.0\%) patients. This was followed by Kaposi's sarcoma in 5 (25.0\%), squamous cell carcinoma in $4(20.0 \%)$, neurofibrosarcoma and liposarcoma in 1 (5.0\%) patient each respectively.

A total of 287 (95.7\%) patients were treated as inpatients and the remaining $13(4.3 \%)$ patients were treated as outpatients. The vast majority of patients, 270 (90.0\%) were treated surgically (Figure 3 ). The remaining 30 (10.0\%) patients were treated conservatively (non-surgical approach) with daily dressing, antimicrobial agents, compression bandage, antibiotics.

A total of 178 post-operative complications were recorded in 175 (58.3\%) patients. Of these, surgical site infection $(77.5 \%)$ was the most common post-operative complications (Figure 4). Table 2 shows predictors of postoperative complications among patients with 


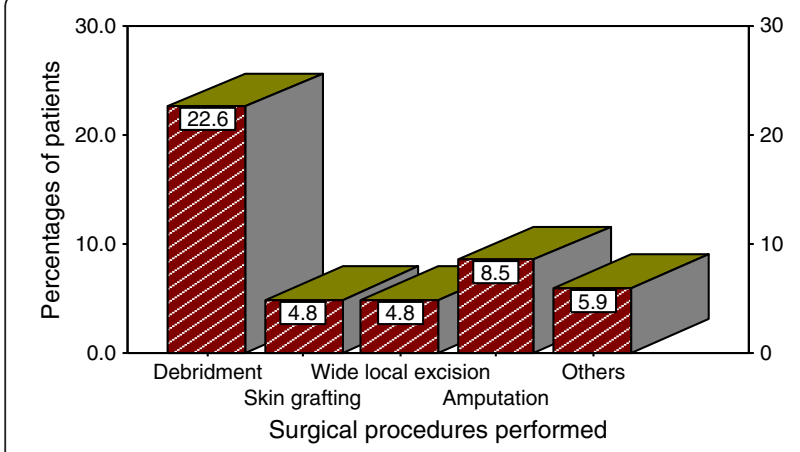

Figure 3 Distribution of patients according to surgical procedure performed.

chronic lower limb ulcers according to univariate and multivariate logistic regression analysis

The overall length of hospital stay (LOS) ranged from 1 day to 180 days with a median of 23 days. The LOS for non-survivors ranged from 1 day and 42 days (median $=10$ days). Table 3 shows predictors of LOS among patients with chronic lower limb ulcers according to univariate and multivariate logistic regression analysis

In this study, thirteen patients died giving a mortality rate of $4.3 \%$. The causes of death were complications of diabetes mellitus (5 patients), HIV infection (4 patients) and advanced malignancy (2 patients). The cause of death was not established in 2 patients.

Out of the two hundred and eighty-seven (95.7\%) survivors, $253(91.6 \%)$ were treated successfully and discharged well (healed). Thirteen (4.5\%) patients were discharged with permanent disabilities resulting from lower limb amputation and the remaining six (2.1\%) patients were discharged home advised to continue with daily dressing at their nearby health facilities. Thirteen (4.5\%) patients were treated as outpatients and two $(0.7 \%)$ patients discharged themselves against medical advice.

\section{Discussion}

In this review, chronic lower limb ulcers were in the third decade of life and tended to affect more males than

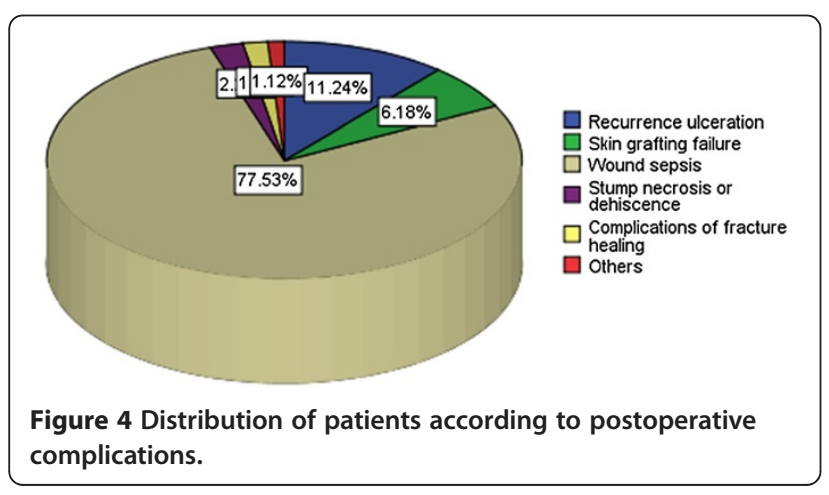

females, with a male to female ratio of 2:1 which is comparable with other studies in developing countries $[16,17]$. Our demographic profile is in sharp contrast to what is reported in developed countries where the majority of the patients are in the sixth decade and above [17-19]. Male predominance in this age group may be due to their increased susceptibility to trauma which was found to be the major etiological agent of chronic lower limb ulcers in this study.

The presence of pre-morbid illness, such as diabetes mellitus, chronic obstructive pulmonary disease, arteriosclerosis, peripheral vascular disease, heart disease, and any conditions leading to hypotension, hypovolaemia, edema, and anemia has been reported elsewhere to have an effect on the outcome of patients with chronic lower limb ulcers [20,21]. Pre-morbid illnesses influence the healing process as a result of their influence on a number of bodily functions [20-23]. In the presence study, diabetes mellitus was the most common premorbid illness accounting for $59.3 \%$ of cases which is agreement with other studies in developing countries [21,22,24]. Diabetes mellitus is associated with delayed cellular response to injury, compromised cellular function at the site of injury, defects in collagen synthesis, and reduced wound tensile strength after healing. Diabetes-related peripheral neuropathy, reducing the ability to feel pressure or pain, contributes to a tendency to ignore pressure points and avoid pressure relief strategies [25].

In the present study, cigarette smoking was reported in $22.7 \%$ of cases which is in keeping with other studies $[26,27]$. Cigarette smoking has been reported to have an impact on wound healing through impairment of tissue oxygenation and local hypoxia via vasoconstriction [28]. Tobacco smoke has high concentration of carbon monoxide, which binds hemoglobin, forming carboxyhemoglobin. Carboxyhemoglobin binds to oxygen with high affinity and thereby interferes with normal oxygen delivery to hypoxic tissues [29].

The etiological pattern of chronic lower limb ulcers have been reported in literature to vary from one part of the world to another depending on the prevailing sociodemographic and environmental factors [2,9]. In Western societies, most chronic lower limb ulcers are due to vascular diseases, whereas in developing countries, trauma, infections, malignancies and poorly controlled diabetes remain the most common causes of chronic lower limb ulceration $[2,9,10]$. In the present study, traumatic ulcers secondary to road traffic accidents were the most common type of chronic lower limb ulcers accounting for more than sixty percent of cases, which is in keeping with other studies done in developing countries $[9,10,20,21]$. High incidence of traumatic ulcers secondary to road traffic accidents may be attributed to recklessness and negligence of the driver, poor 
Table 2 Predictors of Postoperative complications according to univariate and multivariate logistic regression analysis

\begin{tabular}{|c|c|c|c|c|c|c|c|c|}
\hline \multirow[t]{2}{*}{ Predictor (Independent) variables } & \multicolumn{2}{|c|}{ Post operative complications n (\%) } & \multicolumn{3}{|c|}{ Univariate analysis } & \multicolumn{3}{|c|}{ Multivariate analysis } \\
\hline & Absent & Present & OR & $95 \% \mathrm{Cl}$ & $P$ value & OR & $\mathrm{Cl}$ & $P$ value \\
\hline \multicolumn{9}{|l|}{ Age } \\
\hline$\leq 20$ & $39(48.8)$ & $41(51.3)$ & & & & & & \\
\hline$>20$ & $83(37.7)$ & $137(62.3)$ & 1.6 & $0.9-2.6$ & 0.087 & 3.0 & $1.4-6.3$ & 0.004 \\
\hline \multicolumn{9}{|l|}{ Sex } \\
\hline Male & 102(51.0) & $98(49.0)$ & & & & & & \\
\hline Female & $20(20.0)$ & $80(80.0)$ & 4.2 & $2.4-7.3$ & $<0.001$ & 4.3 & $2.1-8.7$ & $<0.001$ \\
\hline \multicolumn{9}{|l|}{ HIV status } \\
\hline Positive & $4(20.0)$ & 16(80.0) & & & & & & \\
\hline Negative & $118(42.1)$ & 162(57.9) & 2.9 & $0.9-8.9$ & 0.062 & & & \\
\hline \multicolumn{9}{|l|}{ CD4 count } \\
\hline 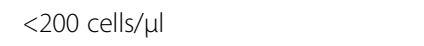 & $1(50.0)$ & $1(50.0)$ & & & & & & \\
\hline$\geq 200$ cells $/ \mu \mathrm{l}$ & $3(23.1)$ & 10(76.9) & 1.3 & $0.2-2.7$ & 0.082 & & & \\
\hline \multicolumn{9}{|l|}{ Pre-morbid illness } \\
\hline Absent & $11(20.4)$ & $43(79.6)$ & & & & & & \\
\hline Present & $111(45.1)$ & 135(54.9) & 3.2 & $1.6-6.5$ & 0.001 & 0.4 & $0.2-1.0$ & 0.041 \\
\hline \multicolumn{9}{|l|}{ Tobacco smoking } \\
\hline Yes & $30(44.1)$ & $38(55.9)$ & & & & & & \\
\hline No & $92(39.7)$ & $140(60.3)$ & 1.9 & $0.4-5.4$ & 0.897 & & & \\
\hline \multicolumn{9}{|l|}{ Duration of illness } \\
\hline $1 / 12-3 / 12$ & $115(48.7)$ & $121(51.3)$ & & & & & & \\
\hline $3 / 12-1$ year & $3(7.1)$ & 39(92.9) & 12.4 & $3.7-41.1$ & $<0.001$ & 8.0 & $2.1-30.0$ & 0.002 \\
\hline$>1$ year & $4(18.2)$ & 18(81.8) & 4.3 & $1.4-13.0$ & 0.010 & & & \\
\hline \multicolumn{9}{|l|}{ Type of ulcer } \\
\hline Traumatic ulcer & 107(59.1) & $74(40.9)$ & & & & & & \\
\hline Vascular ulcer & $4(36.4)$ & $7(63.6)$ & 2.5 & $0.7-9.0$ & 0.150 & & & \\
\hline Neoplastic ulcer & $4(20.0)$ & $16(80.0)$ & 5.8 & $1.9-18.0$ & 0.002 & & & \\
\hline Infective ulcer & $3(7.0)$ & 40(93.0) & 19.3 & $5.7-64.7$ & $<0.001$ & 17.6 & $4.7-66.0$ & $<0.001$ \\
\hline Metabolic ulcer & $2(5.7)$ & $33(94.3)$ & 23.9 & $5.6-102.5$ & $<0.001$ & 8.4 & $1.8-39.4$ & 0.007 \\
\hline Neuropathic ulcer & $2(25.0)$ & $6(75.0)$ & 4.3 & $0.9-22.1$ & 0.077 & & & \\
\hline Ulcerating skin disease & $0(0.0)$ & $2(100)$ & - & - & - & & & \\
\hline \multicolumn{9}{|l|}{ Ulcer size in cm } \\
\hline$\leq 5$ & $90(47.9)$ & $98(52.1)$ & & & & & & \\
\hline$>5-10$ & 28(31.8) & $60(68.2)$ & 2.0 & $1.2-3.4$ & 0.013 & & & \\
\hline$>10$ & $4(16.7)$ & 20(83.3) & 4.6 & $1.5-13.9$ & 0.007 & & & \\
\hline \multicolumn{9}{|l|}{ Mode of treatment } \\
\hline Conservative & 14(36.8) & $24(63.2)$ & & & & & & \\
\hline Surgical & $108(41.2)$ & 154(58.8) & 0.8 & $0.4-1.7$ & 0.608 & & & \\
\hline
\end{tabular}

maintenance of vehicles, driving under the influence of alcohol or drugs and complete disregard of traffic laws.

In agreement with other studies in developing countries $[3,24]$, the majority of patients in the present study presented late to hospital with advanced and complicated chronic lower limb ulcers which may end up being treated by limb amputation with increased risk of recurrence and malignant change. Late presentation in this study may be attributed to poor economic capabilities in cost shared healthcare systems, inadequate knowledge of self-care and socio-cultural reasons. Other contributing factors for late presentation include attempts at home 
Table 3 Predictors of length of hospital stay (LOS) among patients with chronic lower limb ulcers according to univariate and multivariate logistic regression analysis

\begin{tabular}{|c|c|c|c|c|c|c|c|c|}
\hline \multirow[t]{2}{*}{ Predictor (Independent) variables } & \multicolumn{2}{|c|}{ LOS n (\%) } & \multicolumn{3}{|c|}{ Univariate analysis } & \multicolumn{3}{|c|}{ Multivariate analysis } \\
\hline & $\leq 14$ & $>14$ & OR & $95 \% \mathrm{Cl}$ & $\mathrm{P}$ - value & OR & $\mathrm{Cl}$ & P-value \\
\hline \multicolumn{9}{|l|}{ Age } \\
\hline$<20$ & $14(17.5)$ & $66(82.5)$ & 1 & & & & & \\
\hline$>20$ & $45(20.4)$ & 175(79.6) & 1.1 & $0.4-1.6$ & 0.570 & & & \\
\hline \multicolumn{9}{|l|}{ Sex } \\
\hline Male & $42(21.0)$ & 158(79.0) & 1 & & & & & \\
\hline Female & $17(17.0)$ & 83(83.0) & 1.3 & $0.7-2.4$ & 0.412 & & & \\
\hline \multicolumn{9}{|l|}{ HIV status } \\
\hline Positive & $2(10.0)$ & 18(90.0) & 1 & & & & & \\
\hline Negative & $57(20.4)$ & $223(79.6)$ & 2.3 & $0.5-10.2$ & 0.273 & & & \\
\hline \multicolumn{9}{|l|}{ Pre-morbid illness } \\
\hline Absent & $51(20.7)$ & 195(79.3) & 1 & & & & & \\
\hline Present & $8(14.8)$ & $46(85.2)$ & 1.5 & $0.7-3.4$ & 0.324 & & & \\
\hline \multicolumn{9}{|l|}{ Duration of illness } \\
\hline $1 / 12-3 / 12$ & $47(19.9)$ & 189(80.1) & 1 & & & & & \\
\hline $3 / 12-1$ year & $7(16.7)$ & 35(83.3) & 1.2 & $0.5-3.0$ & 0.624 & & & \\
\hline$>1$ year & $5(22.7)$ & 17(77.3) & 0.8 & $0.3-2.4$ & 0.753 & & & \\
\hline \multicolumn{9}{|l|}{ Type of ulcer } \\
\hline Traumatic ulcer & $42(23.2)$ & 139(76.8) & 1 & & & & & \\
\hline Vascular ulcer & $2(18.2)$ & $9(81.8)$ & 1.4 & $0.3-6.5$ & 0.701 & & & \\
\hline Neoplastic ulcer & $4(20.0)$ & $16(80.0)$ & 1.2 & $0.4-3.8$ & 0.746 & & & \\
\hline Infective ulcer & $6(14.0)$ & $37(86.1)$ & 1.9 & $0.7-4.7$ & 0.189 & & & \\
\hline Metabolic ulcer & $3(8.6)$ & $32(91.4)$ & 3.2 & $0.9-11.1$ & 0.063 & 3.5 & $1.0-12.5$ & 0.056 \\
\hline Neuropathic ulcer & $1(12.5)$ & $7(87.5)$ & 2.1 & $0.3-17.7$ & 0.489 & & & \\
\hline Ulcerating skin disease & $1(50.0)$ & $1(50.0)$ & 0.3 & $0.01-4.9$ & 0.401 & & & \\
\hline \multicolumn{9}{|l|}{ Ulcer size in cm } \\
\hline$\leq 5$ & $38(20.2)$ & 150(79.8) & 1 & & & & & \\
\hline$>5-10$ & 17(19.3) & $71(80.7)$ & 1.1 & $0.6-2.0$ & 0.862 & & & \\
\hline$>10$ & $4(16.7)$ & $20(83.3)$ & 1.3 & $0.4-3.9$ & 0.682 & & & \\
\hline \multicolumn{9}{|l|}{ Mode of treatment } \\
\hline Conservative & $13(34.2)$ & $25(65.8)$ & 1 & & & & & \\
\hline Surgical & $46(17.6)$ & $216(82.4)$ & 2.4 & $1.2-5.1$ & 0.018 & 3.2 & $1.4-7.1$ & 0.005 \\
\hline \multicolumn{9}{|l|}{ Postoperative complications } \\
\hline Absent & $26(21.3)$ & $96(78.7)$ & 1 & & & & & \\
\hline Present & 33(18.5) & $145(81.5)$ & 1.2 & $0.7-2.1$ & 0.553 & & & \\
\hline
\end{tabular}

surgery, trust in faith healers, poor management of acute lower limb ulcers and delayed referral in most health centers and peripheral hospitals.

As reported in other studies [30,31], the leg was the most frequent anatomical site affected in our series and the right side was frequently involved. We could not find the reasons for this anatomical site distribution.

The microbiological profile of chronic ulcers of the lower limbs has application to general principles of treatment as well as institution-specific guidelines for management [32]. In the present study, Pseudomonas aeruginosa was the most frequent gram negative bacteria isolated, whereas gram positive bacteria commonly isolated was Staphylococcus aureus. Similar bacterial profile was reported by Lim et al. [32]. The study also found that most of the pathogens were multiply resistant to the commonly prescribed antibiotics such as Ampicillin, Augmentin, Cotrimoxazole, Tetracycline, gentamicin, 
erythromycin, and Ceftriaxone. Similar antimicrobial susceptibility pattern has been reported previously [33]. These findings reflect the widespread and indiscriminate use of antibiotics, coupled with poor patient compliance and self treatment without prescription among African patients [32,33]. The majority of gram negative isolates were sensitive to Meropenem while gram positive being sensitive to Vancomycin; this could be explained by the fact that these antibiotics are relatively rare in the hospital and are more expensive so they are rarely misused.

The prevalence of HIV infection in the present study was $6.7 \%$ that is relatively similar to that in the general population in Tanzania (6.5\%) [34]. High HIV seroprevalence among patients with CLLUs was reported in a Zimbabwean study [35]. HIV seropositive patients have been reported to have a higher risk of developing postoperative complications and have a greater risk of prolonged hospital stay and mortality $[16,18]$. HIV infection has been reported to increase the risk of wound sepsis and poor healing [35]. However, in the present study, there were no significant differences in the outcome between patients who are HIV infected and those who are non-HIV infected.

Fungal infections have been reported to be common in chronic lower limb ulcers with the prevalence ranging from $4.5 \%-50 \%$ and [36,37], are also responsible for some chronic lower limb ulcers e.g. Madura foot [38,39]. In the present study, fungal infection was not investigated due to logistic problems. This calls for other authors to investigate on this.

Histopathological examination remains the most important definitive diagnostic procedure, and it should be performed on any suspicious lesion or any chronic nonhealing ulcers, especially those with any recent change in appearance or considerable drainage [40]. In the present study, malignant ulcers were histopathologically proven in $8.4 \%$ of cases, a figure closely to $10.4 \%$ reported by Senet et al. [41]. In our study, malignant melanoma was the most frequent histopathological type as previously reported by Chalya et al. [42] at the same centre, but at variant with Senet et al. [41] who reported squamous cell carcinoma as most common histopathological type. This difference in histopathological type reflects geographic differences in exposure to risk factors for developing malignant ulcers. While solar radiation has been suggested as a major cause of malignant melanoma among Caucasians, many of malignant melanoma among black Africans has been reported to be unrelated to solar exposure since they occur on the unexposed plantar of the foot [43-51]. Higher incidence of malignant melanoma in our study may be attributed to repeated trauma and constant pressure on the weight bearing areas of the foot as shoe-wearing is less frequent among people especially those from rural areas [42,52].
In the present study, Kaposi's sarcoma ranked third after squamous cell carcinoma. Since the emergence of HIV infection, there has been a steady increase in the prevalence of KS worldwide [53,54]. The rate of HIV infection among patients with Kaposi's sarcoma in our study was $60 \%$, a figure slightly lower than that reported by Chalya et al. [42]. Thus it is obvious that successful HIV control will go a long way to reduce the incidence of this vascular malignancy.

The treatment of chronic lower limb ulcers requires multidisciplinary approach $[54,55]$. The treatment modalities of chronic lower limb ulcers include surgical treatment (such as wound debridement, wide local excision, split thickness skin graft (STSG) or flap cover, block dissection of the regional nodes and limb amputation in advanced lesions) and non-surgical treatment such daily dressing, compressive bandages and antimicrobial agents bases on drug sensitivity pattern [54,56-58]. In the present study, wound debridement with or without STSG or flap cover was the most common surgical procedure performed which is in keeping with studies done elsewhere [55].

The presence of complications has an impact on the final outcome of patients presenting with chronic lower limb ulcers [21]. Most complications are related to late presentation to hospital following ignorance, treatment at home, cost, poverty, advanced malignancy, premorbid conditions like diabetes mellitus, hypertension, and the treatment choices made and the procedures performed. In the present study a total of 178 complications were recorded in 175 (58.3\%) patients, mostly being post operative complications. Of these, surgical site infections (77.5\%) was the most common post operative complication followed by recurrent ulceration (11.2\%) and skin grafting failure (6.2\%). Callam et al. [21] reported a similar observation.

The length of hospital stay is an important measure of morbidity in which estimates of length of hospital stay are important for financial matters and accurate early estimates so as to facilitate better financial planning by the payers since it takes long for the chronic lower limb ulcers to heal so increasing the costs as well as seen in other studies as well $[16,18]$. In this study, the overall mean length of hospital stay was 28.9 days, a figure which is higher than that reported in other studies $[59,60]$. A mean length of hospital stay of 38.2 days was also reported in Nigerian study [16]. A mean of 36.2 days and 64.2 days were reported in Tanzanian and Nigerian studies respectively $[16,24]$. Prolonged LOS in our study was observed in patients with diabetic foot ulcers and in patients who required surgical treatment.

In this study, the mortality rate was $4.3 \%$ which is relatively lower than that reported in other studies [16]. Mortality rate in the present study was attributed to 
complications of diabetes mellitus, hypertension, HIV infection and advanced malignancy. The causes of death in our study is at variant with a Nigerian study which reported anemic heart failure, septicemia and multiple organ failure as causes of death [16]. Addressing these factors responsible for mortality in our patients is mandatory to be able to reduce mortality associated with chronic lower limb ulcers.

In this study, complete healing at discharge from the hospital was achieved in more than $90 \%$ of the patients, which is comparable with other studies $[16,61]$. This is satisfactorily acceptable to both the patient and the surgical team.

Self discharge by patient against medical advice is a recognized problem in our setting and this is rampant, especially amongst patients with chronic lower limb ulcers [62]. In the present study discharge against medical advice was noted in $0.7 \%$ of cases. Discharge against medical advice in our study is attributed to patients feeling well enough to leave and dissatisfaction with treatment received.

Poor follow up visits after discharge from hospitals remain a cause for concern in most developing countries [63]. These issues are often the results of poverty, long distance from the hospitals and ignorance. In the present study, only $33.1 \%$ of patients were available for follow up at three months, the reasons for low follow up rate at our study may be attributed to long distance from the hospital, lack of funds for transport and feeling of being cured.

Delay in getting histopathological results was the major limitation in this study and this might have affected the treatment outcome of patients who needed this confirmatory diagnostic investigation for definitive treatment.

\section{Conclusion}

Chronic lower limb ulceration remains a major public health problem in this part of Tanzania. Traumatic ulcers are the most common type of chronic lower limb ulcers. The majority of patients in our environment present late when the disease is already in advanced stages predisposing them to increased risk of recurrence, malignant change and limb amputation. Early recognition and aggressive treatment of the acute phase of chronic lower limb ulcers at the peripheral hospitals and close follow-up are urgently needed to improve outcomes of these patients in this environment. Further study looking at the factors associated with late presentation to tertiary health facilities is highly recommended. A population based study is highly needed to be able to assess the better picture of the magnitude of the problem in this region.

\section{Competing interests}

The authors declare that they have no competing interests.

\section{Authors' contributions}

FM conceived the study and did the literature search, participated in data analysis, writing of the manuscript and editing. MDM and BBK participated in the literature search, writing of the manuscript and editing. SEM participated in writing of the manuscript, editing and performed the microbiological analysis. PFR participated in writing of the manuscript, editing and performed the pathological work up. PLC participated in writing of the manuscript, editing, data analysis and submission of the manuscript. JMG coordinated the write-up, editing and supervised the study. All the authors read and approved the final manuscript.

\section{Acknowledgements}

The authors would like to thank all those who participated in the preparation of this manuscript.

\section{Author details}

${ }^{1}$ Department of Surgery, Catholic University of Health and Allied SciencesBugando, Mwanza, Tanzania. ${ }^{2}$ Department of Surgery, Muhimbili University of Health and Allied Sciences, Dar Es Salaam, Tanzania. ${ }^{3}$ Department of Pathology, Catholic University of Health and Allied Sciences- Bugando, Mwanza, Tanzania. ${ }^{4}$ Department of Microbiology, Catholic University of Health and Allied Sciences- Bugando, Mwanza, Tanzania. ${ }^{5}$ Department of Biochemistry and Molecular Biology, Catholic University of Health and Allied Sciences- Bugando, Mwanza, Tanzania.

Received: 28 May 2012 Accepted: 23 September 2012 Published: 28 September 2012

\section{References}

1. Lees TA, Lambert D: Prevalence of lower limb ulceration in an urban health district. Br J Surg 1992, 79(10):1032-1034.

2. Barclay $\mathrm{KL}$, Granby T, Elton PJ: The prevalence of leg ulcers in Hospitals. Hosp Med 1998, 59(11):8.

3. Bricksson SV, Lundeberg T, Malm MA: Placebo-controlled trial of ultrasound therapy in chronic leg ulceration. Scandinavian J Rehabilitation Med 1991, 23(4):211-213.

4. Shaw JE, Boulton AJ: The pathogenesis of diabetic foot problems: an overview. Diabetes 1997, 46(Suppl. 2):58-61.

5. Baker SR, Stacey MC, Jopp-McKay AG: Epidemiology of chronic venous ulcers. Br J Surg 1991, 78:864-867.

6. Phillips TJ: Chronic cutaneous ulcers etiology and epidemiology. J Invest Dermatol 1994, 102(Suppl):38-41.

7. Dormandy JA, Stock G: Critical leg ischaemia its patholophysiology and management. Berlin: Springer Verlag; 1990:7-16.

8. Bugando Medical Centre database: Medical record database.; 2008.

9. London NJ, Donnely R: ABC of arterial and venous disease Ulcerated lower limb. Br Med J 2000, 320:1589-1591.

10. Cleverland TJ, Gaines P: Stenting in peripheral vascular disease. Hosp Med 1999, 60:630-632.

11. Valencia IC, Falabella A, Kirsner RS, Eaglstein WH: Chronic venous insufficiency and venous leg ulceration. J Am Acad Dermatol 2001, 44:401-421.

12. Frykberg RG: Epidemiology of the diabetic foot: ulcerations and amputations. Adv Wound Care 1999, 12:139-141.

13. Windsor AC KA, Somers SS: Manipulation of local and systemic host defence in the prevention of perioperative sepsis. Br J Surg 1995, 82:1460-1467.

14. Kaizer $A B$, Jacobs JK: Cefoxitin versus erythromicin, neomycin and cefozolin in colorectal operation. Importance of duration of surgical procedure. Ann Surg 1983, 198:525-530.

15. Holzheimer RGHW, Thidel A: The challenge of post operative infection; does the surgeon make a difference. Infection Control Epidemol 1997, 18:449-456.

16. Adegbehingbe LMO OO, Olabanji JK, Alatise Ol: Chronic leg ulcer presenting through emergency surgical unit. Internet J Surg 2007, 9(1). doi:10.5580/1051.

17. Chalya PL, Mabula JB, Rambau P, Mchembe MD, Kahima KJ, Chandika AB Giiti G, Masalu N, Ssentongo R, Gilyoma JM: Marjolin's ulcers at a university 
teaching hospitalin Northwestern Tanzania: a retrospective review of 56 cases. World J Surg Oncol 2012, 10:38.

18. Meckkes JR, Loots MA, AC VDW, Bos JD: Causes, Investigation, and treatment of Leg Ulceration. Br J Dermatol 2003, 148(3):388-401.

19. Jull W, Walker N, Hackett N, Jones M, Rodgers A, Birchall N, Norton R, Macmahon S: Leg ulceration and perceived health: a population based case-control study. Brit Geriatr Soc 2004, 33:236-241.

20. Liedberg E, Persson BM: Increased incidence of lower limb amputation for arterial occlusive disease. Acta Orthop Scand 1983, 54:230-234.

21. Margolis DJ, Bilker W, Santanna J, Baumgarten M: Venous leg ulcer: incidence and prevalence in the elderly. J Am Acad Dermatol 2002, 46:381-386.

22. De Silva TES: Surgical options in the management of intransigent leg ulcers. Wounds 2012, 8(1):18

23. Grey EJHK, Enoch S: $A B C$ ofwound healing: venous and arterial leg ulcers. Br Med J 2006, 332(7537):347-350.

24. Chalya PL, Mabula JB, Das RM, Kabangila R, Jaka H, Mchembe DM, Kataraihya JB, Mbelenge N, Gilyoma JM: Sugical management of Diabetic foot ulcers: A Tanzanian University teaching hospital experience. BMC Research Notes 2011, 4:365.

25. American Diabetes Association: consensus development conference on diabetic foot wound care. Diabetes Care 1999, 22:1354-1360

26. US Department of Health and Human Services: In Women and Tobacco. Edited by Sheet F; 2009.

27. US Department of Health and Human Services: Tobacco-Related Mortality. 2009.

28. Jone SK, Tripleff RG: The relationship of cigarette smoking to impaired intra-oral wound healing: a review evidence and implication for patient care. J oral Maxillo Surg 1992, 50:237-240.

29. Nagachinta T, Stephens M, Reitz B, Polk BF: Risk factors for surgical wound infection. Muisory cardiac surgery. S Inf Dis 1987, 156:967-973.

30. Georgios SNL: The evaluation of lower-extremity ulcers. Semin Intervent Radiol 2009, 26(4):286-295.

31. Snyder RJ: Treatment of nonhealing ulcers with allografts. Clin Dermatol 2005, 23(4):388-395.

32. Tao S, Lim, Bibombe PM, Ronan M, Kishore S, Manzoor A, Donna A: Microbiological profile of chronic ulcers of the lower limb: A prospective observational study cohort study. ANZ J Surg 2006, 76(8):688-692.

33. Mawalla BM, Mshana SE, Chalya PL, Imirzalioglu C, Mahalu W: Predictors of surgical site infections among patients undergoing major surgery at Bugando Medical Centre in Northwestern Tanzania. BMC Surg 2011, 11:21.

34. Samaila SA MOA: A histopathological analysis of cutaneous malignancies in a tropical African population. Niger J Surg Res 2005, 7(3-4):300-304.

35. Sibanda M, Sibanda $E$, Jönsson $K:$ A prospective evaluation of lower extremity ulcers in a Zimbabwean population. Int Wound J 2009, 6 (5):361-366

36. English MP, Harman RR: The fungal flora of ulcerated legs. Dermatol $\mathrm{Br} J$ 1971, 84(6):567-581.

37. Hansson $C F$, Swanbeck $G$ : Fungal infections occurring under bandages in leg ulcer patients. Acta Derm Venereol 1987, 67(4):341-345.

38. Lipsky BA: Osteomyelitis of the foot in diabetic patients. Clin Infect Dis 1997, 25:1318-1366.

39. Carrascosa JM, Ribera M, Bielsa I: Bacillary angiomatosis presenting as a malleolar ulcer. Arch Dermatol 1995, 131:963-964.

40. Julius S, Luiz Felipe B, Mello M, Norberto C: Malignancy in chronic ulcers and scars of the leg. Skeletal Radiol 2001, 6:331-337.

41. Sene P, Combemale P, Debure C, Baudot N, Machet L, Aout M, Vicaut E, Lok C: Malignancy and Chronic Leg Ulcers The Value of Systematic Wound Biopsies: A Prospective, Multicenter. Arch Dermatol: Cross-sectional Study; 2012 [Epub ahead of print].

42. Chalya PL, Gilyoma JM, Kanumba ES, Mawala B, Masalu N, Kahima KM, Rambau P: Dermatological malignancies at a University Teaching Hospital in north-western Tanzania: a retrospective review of 154 cases. Tanzan J Health Res 2012, 14:1.

43. Filamer DK, Lisa CK, Geanina P, Constantin AD, Doru TA: Malignant melanoma in African-Americans. Dermatol Online J 2009, 15(2):3.

44. Bellows CF, Fortgang IS, Beech DJ: Melanoma in African-Americans: trends in biological behavior and clinical characteristics over two decades. J Surg Oncol 2001, 78:10-16.
45. Cormier JN, Ding M, Lee JE, Mansfield PF, Gershenwald JE, Ross MI, Du XL: Ethnic differences among patients with cutaneous melanoma. Arch Intern Med 2006, 166:1907-1914.

46. Cress RD, Holly EA: Incidence of cutaneous melanoma among nonHispanic whites, Hispanics, Asians, and blacks: an analysis of california cancer registry data, 1988-93. Cancer Cause Control 1997, 8(2):246-252.

47. Swan MC: Malignant melanoma in South Africans of mixed ancestry: a retrospective analysis. Melanoma Res 2003, 13:415-419.

48. Byrd KM, Hoyler SS, Peck GL: Advanced presentation of melanoma in African Americans. J Am Acad Dermatol 2004, 50:21-24.

49. Giraud RM, Rippey JJ: Malignant melanoma of the skin in Black Africans. $S$ Afr Med J 1975, 49:665-668.

50. Reintgen DS, Cox E, Seigler HF: Malignant melanoma in the American black. Curr Surg 1983, 40:215-217

51. Camain RTA, Sarrat H, Quenum C, Faye I: Cutaneous cancer in Dakar. J Nat Cancer Inst 1972, 48:33-49.

52. Oettle AG: Epidemiology of melanoma in South Africa. In Structure and control of melanocyte. Edited by Della P, Mulbock GE. Berlin: Springer; 1966:292.

53. Mandong BM, Chirdan LB, Anyebe AO, Mannaseh AN: Histopathological study of Kaposi's sarcoma in Jos: A 16 year review. Ann Afr Med 2004, 3:174-176

54. Ruckley CV: Caring for patients with chronic leg ulcer. BMJ 1998, 316:407-408.

55. Rahman IA, Fadeyi A: Epidemiology, etiology, and treatment of chronic leg ulcer: Experience with sixty patients. Ann Afr Med 2010, 9(1):1-4.

56. Oluwatosin OM, Oluwatosin OA, Shokunbi MT: Management of pressure ulceration using fenestrated foam and honey. Quarterly J Hosp Med 1998, 8:264-266.

57. Akinyanju OA: Leg ulceration in sickle cell disease in Nigeria. Trop Geogr Med 1979, 31:87.

58. Durosinmi MA, Esan GJ: Chronic leg ulcers in sickle cell disease. Afr J Med Sci 1991, 20:11-14.

59. Ashry HR LL, Armstrong DG, Lavery DC, van Houtum WH: Cost of diabetesrelated amputations in minorities. J Foot Ankle Surg 1998, 37(3):186-190.

60. Payne BC: Diabetes-related lower-limb amputations in Australia. MJA 2000, 173(7):352-354

61. Rahman GA Al, Fadeyi A: Epidemiology, etiology, and treatment of chronic leg ulcer: Experience with sixty patients. Ann Afr Med 2010, 9:1-4.

62. Saitz R: Discharges against medical advice: time to address the causes. CMAJ 2002, 167(6):647-648.

63. Stephen W, Hwang JL, Gupta R, Chien V, Rochelle EM: What happens to patients who leave hospital against medical advice. CMAJ 2003, 168(4):417-420.

doi:10.1186/1471-5945-12-17

Cite this article as: Mbunda et al.: Experiences with Surgical treatment of chronic lower limb ulcers at a Tertiary hospital in northwestern Tanzania: A prospective review of 300 cases. BMC Dermatology 2012 12:17.

\section{Submit your next manuscript to BioMed Central and take full advantage of:}

- Convenient online submission

- Thorough peer review

- No space constraints or color figure charges

- Immediate publication on acceptance

- Inclusion in PubMed, CAS, Scopus and Google Scholar

- Research which is freely available for redistribution 